\title{
ON THE SCALING LAWS FOR JET NOISE IN SUBSONIC AND SUPERSONIC FLOW
}

\author{
M. Kandula* \\ Dynacs Inc., Kennedy Space Center, FL 32899 \\ B. Vu† \\ NASA Kennedy Space Center, FL 32899
}

\begin{abstract}
The scaling laws for the simulation of noise from subsonic and ideally expanded supersonic jets are examined with regard to their applicability to deduce full scale conditions from small-scale model testing. Important parameters of scale model testing for the simulation of jet noise are identified, and the methods of estimating fullscale noise levels from simulated scale model data are addressed. The limitations of cold-jet data in estimating high-temperature supersonic jet noise levels are discussed. It is shown that the jet Mach number (jet exit velocity/sound speed at jet exit) is a more general and convenient parameter for noise scaling purposes than the ratio of jet exit velocity to ambient speed of sound. A similarity spectrum is also proposed, which accounts for jet Mach number, angle to the jet axis, and jet density ratio. The proposed spectrum reduces nearly to the well-known similarity spectra proposed by $\mathrm{Tam}^{1}$ for the large-scale and the fine-scale turbulence noise in the appropriate limit.
\end{abstract}

\section{NOMENCLATURE}

$A=$ jet cross sectional area

$c=$ sound velocity

$\boldsymbol{d}_{j}=$ jet exit diameter, characteristic length

$f=$ frequency

$F_{t}=$ thrust

$I=$ sound intensity $=\overline{p^{2}} / \rho c$

$I^{\prime}=$ normalized acoustic far field intensity

$L=$ characteristic length scale of eddies

$\boldsymbol{m}=$ mass flow rate

$\boldsymbol{M}=$ Mach number

$p=$ pressure

$P=$ sound power $=4 \pi r^{2} I$

$\boldsymbol{P}^{\prime}=$ sound power per unit volume

$r=$ distance from the sound source

$R=$ gas constant

$\operatorname{Re}=$ Reynolds number $=\rho_{j} u_{j} d_{j} / \mu_{j}$

$$
\begin{aligned}
& S t=\text { Strouhal number }=f d_{j} / u_{j} \\
& T=\text { temperature } \\
& u=\text { velocity } \\
& x=\text { axial distance from the nozzle exit plane } \\
& y=\text { radial distance from the jet axis } \\
& v_{i}=\text { turbulent velocity fluctuation } \\
& W_{m}=\text { mechanical power }
\end{aligned}
$$

\section{GREEK SYMBOLS}

$$
\begin{aligned}
& \delta_{i j}=\text { Kronecker delta } \\
& \mu=\text { dynamic viscosity } \\
& \rho=\text { density } \\
& \lambda=\text { wavelength } \\
& \gamma=\text { isentropic exponent } \\
& \theta=\text { angle from the jet axis } \\
& \eta=\text { acoustic intensity } \\
& \omega=\text { solid angle } \\
& \omega_{f}=\text { characteristic frequency of the eddies }
\end{aligned}
$$

\section{SUBSCRIPTS}

$$
\begin{aligned}
& a v=\text { average } \\
& c=\text { chamber condition } \\
& f=\text { full scale } \\
& j=\text { jet } \\
& m=\text { model } \\
& \text { ref }=\text { reference condition } \\
& \infty=\text { ambient fluid }
\end{aligned}
$$

\section{INTRODUCTION}

The generation of noise from turbulent jets is of great practical interest in the design of jet engines (subsonic and supersonic civil transport) and the study of launch vehicle acoustics. Acoustic loads in a launch vehicle environment induce structural vibration of vehicle components, ground support structures and equipment in the immediate vicinity of the launch pad. In the design of launch vehicles, it

*Principal Investigator, Associate Fellow ALAA

†Lead, Launch Systems Testbed, Member ALAA 
is highly desirable that data on acoustic loads (near-field and far-field noise levels) be generated both analytically and from testing of small-scale and full-scale models. Since full-scale acoustic and vibration testing is often cost-prohibitive, the option of small-scale testing combined with analysis methods remains as a practical alternative.

Noise from subsonic jets is mainly due to turbulent mixing, comprising the contributions of large-scale and fine-scale structures. ${ }^{2,3}$ The turbulent mixing noise is mainly broadband. In perfectly expanded supersonic jets (nozzle exit plane pressure equals the ambient pressure), the large-scale mixing noise manifests itself primarily as Mach wave radiation caused by the supersonic convection of turbulent eddies with respect to the ambient fluid. In imperfectly expanded supersonic jets, additional noise is generated on account of broadband shock noise and screech tones.

Scale models are often used in early design stage as a means of predicting the acoustic environment associated with flight vehicles. A detailed knowledge of the mechanisms of noise generation and noise radiation by jets is essential in designing a scale model of the noise source. ${ }^{4}$ In order to ensure complete similarity between model and full scale, we need to ensure similarity of flow, noise generation, and noise propagation.

In practice, it is generally difficult to duplicate (simulate) all the characteristic parameters in the scale model. Model testing with even smaller rocket engines requires extensive safety precautions. Heated jet facilities also involve considerable complexity and cost. The use of less expensive facilities or lower gas temperatures, for example, would considerably simplify model testing. ${ }^{4}$ The ability to conduct a scale model test with a substitute gas (air, nitrogen, helium, etc.) results in considerable savings (reduced costs of test facilities, test time) and advantages. For example, helium-air mixture jets for simulating hightemperature effects have been studied by Kinzie and McLaughlin. ${ }^{5}$ These substitute gas tests require some compromise of the actual physics of the hot jet.

In the absence of an exact match between the dimensionless parameters of the scale model and the full scale, a detailed knowledge of the functional relationship respecting the various parameters is essential to aid in the interpretation of scale model data to predict the full-scale environment. The purpose of this report is to review the scaling laws for simulating noise from both subsonic jets and ideally expanded supersonic jets on the basis of both theoretical considerations and experimental data.

\section{DYNAMIC SIMILARITY}

A schematic of the jet configuration is shown in Fig. 1. In general the sound pressure is a function of several variables

$$
p=p\left(u_{j}, c_{j}, \rho_{j}, T_{j}, d_{j}, \gamma_{j}, \mu_{j}, u_{\infty}, c_{\infty}, \rho_{\infty}, T_{\infty}, f, \theta\right)
$$

From dynamic similarity considerations, the sound power can be expressed in a dimensionless form as

$$
\frac{\overline{p^{2}}}{\left(\rho_{j} u_{j}^{2}\right)^{2}}=f\left[M_{j},\left(\frac{c_{j}}{c_{\infty}}\right),\left(\frac{\rho_{j}}{\rho_{\infty}}\right),\left(\frac{d_{j}}{r}\right), S t, \theta, \operatorname{Re},\left(\frac{u_{\infty}}{c_{\infty}}\right)\right]
$$

In the above, the jet Mach number $\boldsymbol{M}_{\boldsymbol{j}}$, the Strouhal number $S t$, and the Reynolds number Re are defined by

$$
M_{j}=\frac{u_{j}}{c_{j}}, \quad S t=\frac{f d_{j}}{u_{j}}, \quad \operatorname{Re}=\frac{\rho_{j} u_{j} d_{j}}{\mu_{j}}
$$

where sound speeds $c_{j}$ and $c_{\infty}$ in the jet and the ambient are defined by

$$
c_{j}=\sqrt{\gamma_{j} R_{j} T_{j}}, \quad c_{\infty}=\sqrt{\gamma_{\infty} R_{\infty} T_{\infty}}
$$

\section{MECHANISMS OF NOISE GENERATION AND THEORETICAL CONSIDERATIONS}

\section{Isothermal Jets}

\section{Lighthill's Theory for Subsonic Jets}

Lighthill ${ }^{2,3}$ has shown by an acoustic analogy that aerodynamic sound is a consequence of turbulence, which provides a quadrupole source distribution in an ideal gas at rest. The dominant effect of steady low-speed solenoidal convection has been accordingly developed in terms of an inhomogeneous wave equation (derived on the basis of continuity and momentum equations) of the form ${ }^{6}$

$$
\frac{\partial^{2} \rho}{\partial t^{2}}-c_{\infty}^{2} \nabla^{2} \rho=\frac{\partial^{2} T_{i j}}{\partial x_{i} \partial x_{j}}
$$

where the LHS represents the acoustic wave propagation, and the RHS contains the sources that generate the noise field. The quantity $T_{i j}$ is the Lighthillian acoustic tensor 
$\mathrm{T}_{i j}=\rho v_{i} v_{j}+\left(p_{i j}-c_{\infty}^{2} \rho\right) \delta_{i j}=\rho v_{i} v_{j}+\left(p-c_{\infty}^{2} \rho \delta_{i j}\right)+\tau_{i j}$

where $v_{i}$ is the velocity, $\boldsymbol{p}$ the local pressure, and $\tau_{i j}$ the viscous compressive stress tensor. Here the first term represents the contribution of momentum flux, which is important in cold flow (no marked temperature differences exist), so that only the first term is retained:

$$
T_{i j}=\rho v_{i} v_{j}
$$

Lighthill ${ }^{2}$ obtained a formal solution of the Eq. (5a) with the aid of Green's functions. By the application of dimensional analysis to the formal solution, the acoustic power from isothermal subsonic jets is theoretically shown to be

$$
P=K \rho_{\infty} u_{j}^{8} c_{\infty}^{-5} d_{j}^{2}
$$

where $K$ is a proportionality constant, called the acoustic power coefficient. ${ }^{3}$ This relation is the celebrated Lighthill's $\boldsymbol{u}_{j}^{8}$ law for subsonic jets. Subsonic cold-jet data confirm the $u_{j}^{8}$ dependence, as seen in Fig. 2, which is adapted from Ffowcs Williams, ${ }^{7}$ as reproduced from Chobotov and Powell. ${ }^{8}$ The acoustic efficiency for subsonic cold jets is thus expressed as

$$
\eta=\frac{P}{W_{m}}=\frac{\text { acoustic power }}{\text { jet mechanical power }} \propto u_{j}^{5}
$$

where the jet mechanical power $\boldsymbol{W}_{\boldsymbol{m}}$ can be expressed in terms of the thrust $F_{t}$ as

$$
\begin{aligned}
& W_{m}=0.5 F_{t} u_{j}, \\
& F_{t}=m_{j} u_{j}=\rho_{j} u_{j}^{2} A_{j}=\rho_{j} u_{j}^{2}\left(\frac{\pi}{4} d_{j}^{2}\right)
\end{aligned}
$$

with the expression for the thrust applicable for perfectly expanded jets.

\section{Effect of Source Convection}

The above theory holds only for stationary sources. Since quadrupoles are convecting downstream, the effect of moving sources on the direction of noise radiation is accounted for by a convection factor 7,9

$$
P(\theta)=K \rho_{\infty} u_{j}^{7.5} c_{\infty}^{-5} d_{j}^{2} C^{-5}
$$

where $\boldsymbol{C}\left(\boldsymbol{M}_{c}, \theta\right)=\left[\left(1-\boldsymbol{M}_{c} \cos \theta\right)^{2}+\alpha^{2} \boldsymbol{M}_{c}^{2}\right]^{1 / 2}$

Here $\theta$ is the angle from the jet axis, $\boldsymbol{M}_{\boldsymbol{c}}$ the convection Mach number, and $\alpha$ accounts for finite decay time of the eddies. The convection Mach number $\boldsymbol{M}_{\boldsymbol{c}}$ is defined as the effective Mach number of the convecting turbulent eddies in the mixing regions, and may be approximately related to the jet Mach number in a stationary ambient as

$$
M_{c}=0.55 M_{j}
$$

The quantity $\alpha$ is defined as

$$
\alpha^{2}=\omega_{f}^{2} L^{2} /\left(\pi x_{\infty}^{2}\right) \approx \text { const }
$$

where $\omega_{f}$ and $\boldsymbol{L}$ represent the characteristic frequency and length scale of the eddies, respectively. An integration of the sound power over all solid angles yields that

$$
P=\frac{1}{4 \pi} \int_{0}^{\pi} P(\theta) 2 \pi \sin \theta d \theta
$$

so that $\quad P=K \rho_{\infty} u_{j}^{7.5} c_{\infty}^{-5} d_{j}^{2}\left(C^{-5}\right)$ av

where $\left(C^{-5}\right)_{a v}=\frac{1}{3 M_{c}^{5}}\left[\frac{z\left(2 z^{2}+3 \alpha^{2} M_{c}^{2}\right)}{z^{2}+\alpha^{2} M_{c}^{2}}\right]_{z=1-M_{c}}^{1+M_{c}}$

represents the mean amplification factor. ${ }^{10}$

The nonsingular factor $C^{-5}$ in Eq. (9) replaces the idealized factor $\left(1-M_{c} \cos \theta\right)^{-5}$ introduced by Lighthill, ${ }^{2}$ amounting to very large decay time of eddies, thereby leading to $\left(C^{-5}\right)_{a v}=\left(1+M_{c}^{2}\right) /\left(1-M_{c}^{2}\right)^{4}$. The exponent was corrected by Ffowcs Williams ${ }^{11}$ from -6 to -5 . It is shown that the simple expression of Lighthill exaggerates the directivity by up to $10 \mathrm{~dB}$ at turbojet flow speeds. ${ }^{10}$

Fig. 3 shows the variation of the mean convective amplification factor with $\boldsymbol{M}_{\boldsymbol{c}}$ for a typical value of $\alpha=0.4$. This amplification factor is seen to slowly increase with $M_{c}$ in the subsonic range, providing a $u_{j}^{8}$ dependence in the low speed region. ${ }^{10}$ It ultimately approaches $M_{c}^{-5}$ dependence at high Mach numbers.

A polar plot of the variation of directivity of jet noise (relative to $\theta=90 \mathrm{deg}$ ) at various Mach numbers is ex- 
hibited in Fig. 4a. Fig. 4b presents a linear plot of the directivity of the jet noise considered in Fig. 4a. The directivity at increased Mach numbers is clearly evident. Experimental data suggest the existence of a refractive dip close to the jet axis as a result of refraction by the mean flow. A discussion of the effects of refraction in the scaling law is beyond the scope of the present paper. Directivity and spectral effects of shear-noise (due to joint contribution of turbulence and mean flow) is also not considered here, and only self-noise due to turbulence is accounted for.

\section{$\underline{\text { Supersonic Jets }}$}

An examination of Fig. 2 suggests that the $u_{j}^{8} d_{j}^{2}$ law of Lighthill for subsonic flow breaks down at high exhaust velocities, where the convection velocities of the eddies in the turbulent mixing region approaches supersonic values. At the high exhaust velocities of present today rocket engines, this law predicts a physically unrealistic result that over $100 \%$ of the jet propulsive power is converted to noise. ${ }^{12}$ Experimental data suggest a $\boldsymbol{u}^{6}$ dependence of the sound power level for supersonic jets of low Mach numbers $\left(\boldsymbol{M}_{\boldsymbol{j}}=1\right.$ to 1.5$)$. At higher Mach numbers, a $\boldsymbol{u}_{j}^{4}$ dependence is noted by the measurements at Mach 2.5 (Ref. 13), as reviewed by Sutherland. ${ }^{14}$ These trends are consistent with the measurements by Cole et al., ${ }^{15}$ as reviewed by McInerny. ${ }^{16}$ At still larger Mach number (in excess of about 2.5), a $u_{j}^{3}$ dependence of sound power level is observed. The $u_{j}^{3}$ dependence of sound power implies a constant acoustic efficiency independent of jet velocity.

As noted by Ffowcs Williams, ${ }^{7}$ possible mechanism of sound generation by supersonic shear layers is quite different from that indicated by Lighthill ${ }^{2}$ for low-speed subsonic jets. Ffowcs Williams extended Lighthill's theory for high-speed solenoidal convection and predicted a $u^{3}$ dependence of jet noise at high supersonic Mach numbers. $^{7}$ A $u_{j}^{3}$ dependence is also indicated by Tam. ${ }^{17}$ These predictions are in qualitative agreement with the data at high supersonic flow. The departure from the $u_{j}^{8}$ dependence at supersonic speeds may be partly attributed to compressibility effects, causing a reduction in source strength. ${ }^{18}$ At increased Mach numbers, there is a reduction of transverse velocity fluctuations in the mixing layer, as indicated by the data of Goebel and Dutton ${ }^{19}$ and predicted in Kandula and Wilcox.

Phillips ${ }^{21}$ proposed an asymptotic theory for very high values of $u_{j} / c_{\infty}$, according to which the acoustic efficiency must ultimately diminish like $u_{j}^{-3 / 2}$ or the sound power as $u_{j}^{3 / 2}$. There is very limited data at very high Mach numbers to provide a validation of this theory. Also at very high Mach numbers (characteristic of hypersonic regime), real gas effects and property variations can become significant such that the accuracy of the theory becomes questionable.

Based on the foregoing discussion, we may roughly summarize the sound power level dependence in supersonic speeds as follows:

$$
P \propto \begin{cases}u_{j}^{6} & 1.0<M<1.5 \\ u_{j}^{4} & 1.5<M<2.5 \\ u_{j}^{3} & 2.5<M<5\end{cases}
$$

\section{Spectral Distribution}

Powell ${ }^{22}$ first derived a similarity law for sound power spectrum of the form

$$
\begin{array}{rlr}
P(\theta, f) & \sim \frac{\bar{\rho}^{2} u_{j}^{7} d_{j}^{3}}{\rho_{\infty} c_{\infty}^{5} C^{4}}\left(f C / f_{p}\right)^{2} & 0 \leq f \leq f_{p} \\
& \sim \frac{\bar{\rho}^{2} u_{j}^{7} d_{j}^{3}}{\rho_{\infty} c_{\infty}^{5} C^{4}}\left(f C / f_{p}\right)^{-2} & f_{p} \leq f \leq \infty
\end{array}
$$

where $f_{p}$ represents the peak frequency value, $\bar{\rho}$ the local time-averaged density and $C$ is defined by Eq. (10). Ribner ${ }^{10}$ proposed for the self noise a semiempirical spectrum of the form

$$
P(\theta, f)=\frac{\bar{\rho}^{2} u_{j}^{7} d_{j}^{3}}{\rho_{\infty} c_{\infty}^{5} C^{4}} H(v)
$$

$$
\text { where } \quad H(v)=\frac{v^{2}}{\left(1+v^{2}\right)^{2}}, \quad v=f C / f_{p}
$$

which provides the asymptotic behavior according to Eq. (16).

On the basis of a detailed study of jet noise data for sound power spectrum for supersonic and subsonic jets (both hot and cold jets), Tam et al. ${ }^{1}$ postulated (discovered) the existence of two universal similarity spectrum functions $F$ and $G$, such that the overall jet noise spectrum is expressed as

$$
S=\left[A F\left(f / f_{L}\right)+B G\left(f / f_{f}\right)\right]\left(d_{j} / r\right)^{2}
$$


where $F\left(f / f_{L}\right)$ is a spectrum for the large-scale turbulence/instability waves ( characteristic of Mach wave radiation), and $G\left(f / f_{f}\right)$ is the spectrum for the fine-scale turbulence. ${ }^{23}$ The frequencies $f_{L}$ and $f_{f}$ correspond respectively to the peaks of the large-scale turbulence and fine-scale turbulence. These spectrum functions are normalized such that $\boldsymbol{F}(1)=\boldsymbol{G}(1)=1$. Empirical correlations are proposed for the amplitudes $\boldsymbol{A}$ and $\boldsymbol{B}$, and the peak frequencies of the two independent spectra as a function of the jet operating parameters $u_{j} / c_{\infty}, T_{c} / T_{\infty}$ and the inlet angle $\theta$. It is shown that the noise due to large-scale structure is dominant at small angles to the jet axis and that the fine-scale structure is dominant in the forward quadrant.

Fig. 5 displays the two universal similarity spectra of Tam for large-scale turbulence noise and fine-scale turbulence noise. ${ }^{1}$ For comparison purposes, the empirical spectrum due to Ribner ${ }^{10}$ is also presented. It is interesting to note that the Ribner spectrum matches well with the large-scale turbulence noise spectrum for frequencies below the peak frequency, whereas it compares better with Tam's fine-scale turbulence noise spectrum beyond the peak frequency except at very large frequencies.

\section{Heated Jets}

\section{Experimental Considerations}

Whereas cold jets have been the subject of many investigations, relatively little research has been devoted to the topic of heated jets. ${ }^{24}$ While in commercial transport applications (turbojets), the jet temperature is of the order of $1000^{\circ} \mathrm{F}\left(\boldsymbol{M}_{j}=0.6\right.$ to 0.9$)$, the temperatures in rocket exhausts are considerably higher and are of the order of $2000^{\circ} \mathrm{F}\left(M_{j}=2.5\right.$ to 3.5$)$. Although cold air jets can be used to determine differences in a noise field due to geometric changes, the use of cold air jets to establish absolute values of a full-scale noise field is considered not feasible. ${ }^{4}$ Cold-air tests are thus good to indicate qualitative differences in the acoustic field but are only indicative of the order of magnitude of the actual phenomena of noise reduction.

Data on scale models generally suggest a $5-10 \mathrm{~dB}$ difference between cold- and hot-jet tests. According to a review by Fisher et al., ${ }^{25}$ for a constant mean velocity of the jet, the acoustic levels increase with an increase in mean temperature of the jet for $\boldsymbol{M}_{j}<0.7$ and decrease with an increasing temperature if $\boldsymbol{M}_{j}>0.7$. According to the data of Narayanan et al., ${ }^{26}$ for subsonic jets
$\left(0<M_{j}<0.9\right)$ at a fixed jet velocity, an increase in jet temperature diminishes the sound power level (Fig. 6). On the other hand, at a given jet Mach number $\boldsymbol{M}_{j}$, an increase in jet temperature enhances the sound power level as shown by Morgan et al. ${ }^{4}$ (see Fig. 7). Kinzie and McLaughlin ${ }^{5}$ note that significant differences exist between noise from moderately heated supersonic jets and unheated supersonic jets. Heated air data of Seiner et al. ${ }^{27}$ at $\boldsymbol{M}_{\boldsymbol{j}}=2$ suggest that the peak OASPL is higher at higher temperatures $\left(6 \mathrm{~dB}\right.$ increase as $T_{j}$ increases from 313 to $1534 \mathrm{~K}$ ), as demonstrated in Fig. 8.

Experiments by Tanna ${ }^{28}$ for cold and hot subsonic and supersonic jets show that the spectral content of noise from hot jets is fundamentally different from that of cold jets. There is an order-of-magnitude variation in peak frequency and amplitude, as displayed in Fig. 9, adapted from Fortune and Gervais ${ }^{24}$.

\section{Analyses and Correlations}

In the presence of density differences between the jet fluid and the ambient fluid (such as helium jets in air), the corresponding acoustic power is proposed by $\mathrm{Lighthill}^{3}$ as

$$
P=K \rho_{j}^{2} \rho_{\infty}^{-1} u_{j}^{8} c_{\infty}^{-5} d_{j}^{2}
$$

since the Lighthill's stress tensor contains a factor $\rho_{j}$. With regard to the role of jet temperature, Lighthill points out that inhomogeneities in temperature amplify the sound due to turbulence, just as shear affects high-frequency components of the jet noise. According to Lighthill, the effects of velocity and temperature cannot be separated.

Mani $^{29,30}$ has shown, with the aid of a slug flow approximation, that mean density gradients act to generate dipole and monopole source terms, which produce $M^{6}$ and $M^{4}$ dependence at high jet temperatures for constant value of (jet temperature - ambient temperature), where $\boldsymbol{M}$ denotes the ratio of jet velocity to ambient sound speed.

Morfey et al. ${ }^{18}$ developed scaling laws for both quadrupole and dipole components of turbulent mixing. They proposed an additional mixing noise due to dipole source at high jet temperatures and suggested the following relation for the normalized acoustic far-field intensity $I^{\prime}$ : 


$$
\begin{aligned}
& I^{\prime}=K_{1}\left(\frac{\rho_{j}}{\rho_{\infty}}\right)\left(\frac{c_{j}}{c_{\infty}}\right)^{-4}\left(\frac{u_{j}}{c_{\infty}}\right)^{8}+ \\
& K_{2}\left(\frac{\rho_{j}}{\rho_{\infty}}\right)\left(\frac{c_{j}}{c_{\infty}}\right)^{-2}\left(\frac{\Delta T}{T_{j}}\right)\left(\frac{u_{j}}{c_{\infty}}\right)^{6}
\end{aligned}
$$$$
\text { where } \quad I^{\prime}=\frac{\overline{p^{2}}}{\rho_{\infty}^{2} c_{\infty}^{4}}\left(\frac{r}{d_{j}}\right)^{2}, \quad \Delta T=T_{j}-T_{\infty}
$$

The dipole term is based on theoretical considerations of sound generation by convected density inhomogeneities. It is suggested that, in order to generalize the prediction scheme, the temperature ratio $T_{j} / T_{\infty}$ be replaced by $\left(\rho_{j} / \rho_{\infty}\right)^{-1}$, the density ratio being the dynamically significant quantity.

On similar grounds, Liley $^{31}$ proposed the existence of an additional dipole source term arising from density fluctuations (due to temperature fluctuations) and suggested that the sound power per unit volume of turbulence can be expressed as

$$
P^{\prime \prime}=\alpha_{p} \frac{\rho_{j}^{2}}{\rho_{\infty}} \frac{u_{j}^{8}}{c_{\infty}^{5} d_{j}}+\alpha_{H} \frac{\rho_{j}^{2}}{\rho_{\infty}} \frac{u_{j}^{6}}{c_{\infty}^{3} d_{j}}
$$

According to Liley, the dipole term dominates the quadrupole term at high speeds.

From a detailed study of axisymmetric, supersonic, high-temperature jet noise data of NASA Langley Research Center, including that of Seiner et al., ${ }^{27}$ Tam et al. ${ }^{1}$ proposed correlations for the peak sound pressure level (at $90 \mathrm{deg}$ to the jet axis) for the large-scale turbulence and fine-scale turbulence. For the large-scale turbulence, the correlation for the amplitude $\boldsymbol{A}$ (in $\mathrm{dB} / \mathrm{Hz}$ ) is proposed as

$$
\begin{aligned}
& 10 \log \left(A / p_{\text {ref }}^{2}\right)=75+46 /\left(T_{c} / T_{\infty}\right)^{0.3} \\
& +10 \log \left(u_{j} / c_{\infty}\right)^{n}
\end{aligned}
$$

where

$$
n=10.06-0.495 /\left(T_{c} / T_{\infty}\right) .
$$

The amplitude for the fine-scale turbulence, $B$ (in $\mathrm{dB} / \mathrm{Hz}$ ) is recommended as

$$
\begin{aligned}
& 10 \log \left(B / p_{\text {ref }}^{2}\right)=83.2+19.3 /\left(T_{c} / T_{\infty}\right)^{0.62} \\
& +10 \log \left(u_{j} / c_{\infty}\right)^{n}
\end{aligned}
$$

where

$$
n=6.4+1.2 /\left(T_{c} / T_{\infty}\right)^{1.4}
$$

It is seen from the above relations that the jet temperature has strong effect on the velocity component. In the case of large-scale turbulence, the velocity exponent $n$ for cold jets $\left(T_{c} / T_{\infty}=1\right)$ is approximately equal to 9.5 , which is somewhat larger than 8 , as predicted by the Lighthill's acoustic analogy. In the case of fine-scale turbulence, the velocity exponent $n$ reduces to 7.6 for cold jets $\left(T_{c} / T_{\infty}=1\right)$, in very close agreement with the wellknown subsonic jet value of 8 , as predicted by Lighthill's theory. At a jet temperature ratio of 2 , the value of the exponent reduces to 6.85 .

Recently, Massey et al. ${ }^{32}$ suggested a correction factor for the temperature effects, as based on their data over a range of $\boldsymbol{M}=0.6$ to 1.2 for rectangular jets issuing from converging nozzles:

$$
\begin{aligned}
& \text { OASPL }-10 \log \left[\frac{\rho_{j} \rho_{\infty}}{\rho_{S T P}}\right]\left(\frac{T_{\infty}}{T_{S T P}}\right)^{2}\left(\frac{A_{j}}{r^{2}}\right) \\
& =f_{1}\left[\log \left(\frac{u_{j}-u_{\infty}}{c_{\infty}}\right)\right]
\end{aligned}
$$

where $\boldsymbol{A}_{j}$ represents the jet cross sectional area, and STP referes to the standard conditions.

Calculations by the present authors, using OVERFLOW Navier-Stokes CFD code, ${ }^{33}$ have shown that the length of the supersonic core decreases with an increase in jet temperature, at a constant jet Mach number of 2 and constant ambient temperature (Fig. 10). This suggests that an increase in jet temperature not only introduces dipole sources but also alters the quadrupole source distribution by shortening the core length.

\section{PROPOSED SCALING LAWS}

\section{Sound Power}

Based on a detailed study of the above considerations concerning experimental data and theoretical analyses, refinements to the scaling laws for jet noise are proposed as follows. In accordance with Lighthill-Ffowcs Williams-Ribner formulations, the following expression for the sound power level is proposed for both subsonic and supersonic flow: 


$$
\begin{gathered}
\frac{\overline{p^{2}}(\theta, f)}{\left(\rho_{j} u_{j}^{2}\right)^{2}}=K_{1}\left(\frac{\rho_{\infty}}{\rho_{j}}\right)\left(\frac{u_{j}}{c_{j}}\right)^{4}\left(\frac{c_{j}}{c_{\infty}}\right)^{4}\left(\frac{d_{c}}{r}\right)^{2} \\
G_{1}\left(\frac{u_{j}}{c_{j}}, \theta\right) G_{2}\left(f / f_{p}\right)
\end{gathered}
$$

where $\boldsymbol{K}_{1}$ is a proportionality constant, $\boldsymbol{G}_{1}$ is the directivity factor (owing to source convection), and $\boldsymbol{G}_{2}$ accounts for the distribution of the sound power. The directivity factor is essentially the same as given by Eq. (10) in accordance with Lighthill-Ffowcs Williams-Ribner formulation:

$$
G_{1}=C^{-5}=\left[\left(1-M_{c} \cos \theta\right)^{2}+\alpha^{2} M_{c}^{2}\right]^{-5 / 2}
$$

where a value of $\alpha=0.4$ is considered. The convective Mach number $M_{c}$ is related to the jet Mach number as

$$
M_{c}=0.55 M_{j}=0.55\left(u_{j} / c_{j}\right)
$$

Eq. (26) can also be recast in an alternative form as

$$
\begin{gathered}
\frac{\overline{p^{2}}(\theta, f)}{p_{r e f}^{2}}=K_{1}\left(\frac{c_{j}^{4} \rho_{j}^{2}}{p_{\text {ref }}^{2}}\right)\left(\frac{\rho_{\infty}}{\rho_{j}}\right)\left(\frac{u_{j}}{c_{j}}\right)^{8}\left(\frac{c_{j}}{c_{\infty}}\right)^{4}\left(\frac{d_{c}}{r}\right)^{2} \\
G_{1}\left(\frac{u_{j}}{c_{j}}, \theta\right) G_{2}\left(\frac{f}{f_{p}}\right)
\end{gathered}
$$

For a thermally perfect gas, the density ratio is related to the temperature ratio by

$$
\rho_{j} / \rho_{\infty}=T_{\infty} / T_{j}
$$

Thus for an ideal gas, the temperature dependence of sound power at a constant value of jet Mach number can be characterized as

$$
\left(p_{1}^{2} / p_{2}^{2}\right)=\left(\rho_{j 2} / \rho_{j 1}\right)^{3}=\left(T_{j 1} / T_{j 2}\right)^{3}, M_{j}=\text { const } .(31 \mathrm{a})
$$

On the other hand, for a constant jet velocity, the ratio of sound power becomes

$$
\left(p_{1}^{2} / p_{2}^{2}\right) \approx\left(\rho_{j 1} / \rho 2\right)=\left(T_{j 2} / T_{j 1}\right), \quad u_{j}=\text { const }
$$

where any differences in $\boldsymbol{M}_{\boldsymbol{j}}$ influencing the directivity and spectral distribution through the factors $G_{1}$ and
$G_{2}$ are ignored. Eqs. (31a) and (31b) illuminate the fundamental difference in temperature scaling of sound power. Eq. (31a) suggests an amplification of sound power with increased jet temperature for a fixed value of $\boldsymbol{M}_{\boldsymbol{j}}$, while Eq. (31b) suggests a decreased value of sound power with an increase in jet temperature for a constant value of $u_{j}$.

\section{Similarity Spectrum}

A single similarity spectrum is also proposed here to apply to both subsonic and supersonic flow and to account for both the fine-scale turbulence and turbulence structure associated with Mach wave radiation. A semiempirical spectrum is propose here as

$$
G_{2}=\frac{\left(f / f_{p}\right)^{5 / 4 a}}{\left[1+\left(f / f_{p}\right)^{2}\right]^{9 / 6 a}}
$$

where $a=\left[0.2+\exp \left(-4 M_{c} \cos \theta\left(\rho_{j} / \rho_{\infty}\right)\right)\right]^{0.35}$

The density ratio parameter $\rho_{j} / \rho_{\infty}$ indirectly takes into account the effects of jet temperature on the quadrupole character of the sound source.

The proposed expression is based on Von Karmantype interpolation formula for isotropic turbulence ${ }^{34}$ as suggested by Saffman. ${ }^{35}$ Von-Karman ${ }^{34}$ originally proposed a spectrum of the form

$$
G_{2}=\frac{\left(f / f_{p}\right)^{4}}{\left[1+\left(f / f_{p}\right)^{2}\right]^{7 / 6}}
$$

which covers the range between the permanent largest eddies of $f^{4}$-law (as $f \rightarrow 0$ ) and the Kolmogorov inertial subrange ${ }^{36}$ characterized by the $f^{-5 / 3}$ law at very large values of $f$. Following Saffman, considering a $f^{-2}$ law at $k \rightarrow 0$, Hinze $\mathrm{e}^{35}$ suggests a spectrum of the form

$$
G_{2}=\frac{\left(f / f_{p}\right)^{2}}{\left[1+\left(f / f_{p}\right)^{2}\right]^{7 / 6}}
$$

valid for the turbulent transport of both a vector (velocity and momentum) and a scalar quantity.

The proposed expression, given by Eq. (32), is of more general form, capable of describing the spectrum at 
low and high Mach numbers and accounting for the directivity effects and departures from isothermality. The import of the proposed spectrum is that at high jet Mach numbers the broadband turbulence spectrum degenerates to the narrowband spectrum typical of large-scale turbulence governing Mach wave radiation. It is seen that for the isothermal case, the present spectrum reduces to the following form:

$$
\begin{aligned}
& G_{2} \sim \begin{cases}\left(f / f_{p}\right)^{1.174} & f \rightarrow 0 \\
\left(f / f_{p}\right)^{-1.643} & f \rightarrow \infty\end{cases} \\
& G_{2} \sim\left\{\begin{array}{ll}
\left(f / f_{p}\right)^{2.197} & f \rightarrow 0 \\
\left(f / f_{p}\right)^{-3.074} & f \rightarrow \infty
\end{array} \quad M \rightarrow \infty\right.
\end{aligned}
$$

Recent Direct Numerical Simulation (DNS) data by Bodony and Lele ${ }^{37}$ suggest that, at $\boldsymbol{M}_{\boldsymbol{j}}=1.2$, the spectrum is of the form $f^{-3.33}$ at large values of wave number, which is close to the present result of $f^{-3.074}$.

With regard to noise spectrum due to fine scale turbulence, Morris and Farassat ${ }^{38}$ recently presented a detailed comparison of of predictions from acoustic analogy theories and by the method of Tam and Auriault ${ }^{39}$ involving adjoint Green's function for the linarized Euler equation.

\section{RESULTS AND DISCUSSION}

\section{Overall Sound Power}

The variation of OASPL with the jet Mach number is portrayed in Fig. 11 with the jet temperature ratio as a parameter. The isothermal result is obtained from Eq. (13), and the temperature effects are evaluated from Eq. (31a). The calculations correspond to the perfectly expanded jet. For convenience, the data are plotted with reference to the OASPL value at $\boldsymbol{M}_{j}=1$. As is to be expected, the OASPL transitions from a $u_{j}^{8}$ dependence in subsonic flow to $u_{j}^{3}$ at large supersonic Mach numbers. The transition region corresponds to a range of $M_{j}=1.5$ to 3.0, which in turn translates to a convective Mach number range of 0.825 to 1.65 . Although the calculations are shown for jet Mach numbers of 10 , they should be used with caution for jet Mach numbers in excess of about 5 (hypersonic flow) where real gas effects (including dissociation) can become significant. The results for the isothermal jets $\left(T_{j} / T_{\infty}=1\right)$ appear to be in good agreement with the available data (see Fig. 2). For example, for the isothermal jet, an increase of OASPL of about $60 \mathrm{~dB}$ is noted as the jet Mach number increases from 0.2 to 1.0 (see data of Fig. 2 at $u_{j}=200 \mathrm{ft} / \mathrm{s}$ and $\boldsymbol{u}_{j}=1000 \mathrm{ft} / \mathrm{s}$ ).

Fig. 11 also suggests that, at a given $M_{j}$, OASPL depends only on the temperature ratio, as indicated by Eq. (31a). Comparison of this theory with the data of Morgan ${ }^{4}$ suggests that, at $\boldsymbol{M}_{j}=1$ and a temperature ratio of 3 (jet temperature increased from 60 to $1120^{\circ} \mathrm{F}$ ), the observed increase in OASPL is about $13 \mathrm{~dB}$, while the present scaling law provides a value of 14.3. Referring to the subsonic data of Narayanan, ${ }^{26}$ as seen in Fig. 6, at a constant value of $u_{j} / c_{\infty}=0.891$, a drop of OASPL of about $5 \mathrm{~dB}$ is noted as the jet temperature is increased form 83 to $1000^{\circ} \mathrm{F}$. This compares favorably with a predicted value of about $4.3 \mathrm{~dB}$ according to the present scaling law [Eq. (31b)].

\section{Similarity Spectrum}

The variation of similarity spectrum with Mach number at a constant value of $\theta=20 \mathrm{deg}$ is provided in Fig. 12a. Also shown in this plot are the similarity spectra of $\mathrm{Tam}^{1}$ for large-scale turbulence noise and fine-scale turbulence noise derived on the basis of experimental data of NASA Langley Research Center. The results indicate that at large values of Mach number, the spectrum becomes closer to the similarity spectrum of Tam for large-scale turbulence. As the jet Mach number is reduced, the proposed spectrum becomes progressively broader and approaches the similarity spectrum of Tam for fine-scale turbulence. The intersection of the fine-scale spectrum with the large-scale spectrum at high frequencies, as observed in the similarity spectra of Tam, is absent in the present predictions. Spectral data of Massey et al. ${ }^{32}$ at $\theta=40 \mathrm{deg}$ for a Mach number range of 0.6 to 1.2 qualitatively support this trend.

Referring to Fig. 12b, a comparison of similarity spectra at $M_{j}=2$ for various angles to the jet axis, we see that as the angle is increased from 20 to $90 \mathrm{deg}$, the proposed spectra shifts from a narrow band to a broad band and isgenerally bounded by the similarity spectra of Tam. The comparisons suggest that the narrowband spectrum characterizing the large-scale turbulence noise of Mach wave radiation is likely a perturbation from the fine-scale spectrum. Some evidence to this effect is found from the recent experimental data of Hileman and Samimy ${ }^{40}$, which suggest a rather continuous transition from the narrowband spectrum to a broadband spectrum as the angle of a Mach 1.3 jet is increased from 20 to 90 deg.

Finally, the effect of jet temperature on the sound power spectra is highlighted in Fig. 12c for $M_{j}=2$ and 
$\theta=20 \mathrm{deg}$. Consistent with the measured data, as the jet temperature is increased, the spectrum progressively shifts from a narrowband spectrum to a broadband spectrum.

\section{CONCLUSION}

A review of the scaling and similarity laws applied to jet noise suggests that proper care needs to be exercised in extending small-scale test data to full-scale application. While the phenomenon of noise generation and propagation in subsonic flow has been satisfactorily understood, theory of noise generation in highly supersonic flow is relatively less understood. The effect of jet temperature in supersonic jets leads to additional complication in the understanding of jet noise. The issue of highly supersonic jets at high temperature, typical of launch vehicles, requires further experimental and theoretical study.

With the aid of scaling laws for jet noise proposed here, it has been demonstrated that the jet Mach number, rather than the ratio of jet velocity to ambient sound velocity, is the proper scaling parameter for correlating hightemperature jet noise. The effect of jet temperature is accounted for by Lighthill's suggestion through the changes in the density factor in the quadrupole field. No account, however, was considered as to the importance of diploes and monopoles on the sound field at high jet temperatures, and these considerations need further investigation. The present study, however, suggests that significant jet temperature effects exist insofar as the quadrupole source distributions are concerned.

A continuous similarity spectra is also proposed that is generally bounded by the similarity spectra proposed by Tam for large-scale and fine-scale turbulence. Effects of Mach number and angle from the jet axis are taken into account in the directivity factor, while the effects of Mach number, angle from the jet axis and temperature are accounted for in the similarity spectra. The resulting predictions are in general agreement with the available data.

\section{ACKNOWLEGEMENT}

This work is supported by funding from Air Force Research Laboratory, Wright-Patterson Air Force Base, Ohio, with Gregory Moster as the technical monitor.

\section{REFERENCES}

${ }^{1}$ Tam, C.K.W., Golebiowski, M., and Seiner, J.M., "On the two components of turbulent mixing noise from supersonic jets," AIAA Paper 96-1716, $2^{\text {nd }}$ AIAA/CEAS Aeroacoustics Conference, May 1996.

${ }^{2}$ Lighthill, M.J., "On sound generated aerodynamically, I. General theory," Proc. Roy. Soc. A., 211,1952, pp. 564587.
${ }^{3}$ Lighthill, M.J., "On sound generated aerodynamically, II. Turbulence as a source of sound," Proc. Roy. Soc. A., 222, 1954, pp. 1-32.

${ }^{4}$ Morgan, W.V., Sutherland, L.C., and Young, K.J., "The use of acoustic scale models for investigating near field noise of jet and rocket engines," WADD Technical Report 61-178, Wright-Patterson Air Force Base, Ohio, 1961.

${ }^{5}$ Kinzie, K.W. and McLaughlin, D.K., "Measurements of Supersonic Helium/Air Mixture Jets," AlAA J., Vol. 37, No. 11, 1999, pp. 1363-1369.

${ }^{6}$ Goldstein, M.E., Aeroacoustics, McGraw-Hill, New York, 1976.

${ }^{7}$ Ffowcs Williams, J.E., "The noise form turbulence convected at high speed," Proc. Roy. Soc. A., 255, 469, 1963.

${ }^{8}$ Chobotov, V. and Powell, A., "On the prediction of acoustic environments from rockets," Rama-Wooldridge Corp. Rept. E.M.-7-7, 1957.

${ }^{9}$ Ribner, H.S., "New theory of jet-noise generation, directionality and spectra," J. Acoust. Soc. Amer., Vol. 31, 1962, pp. 245-246.

${ }^{10}$ Ribner, H.S., "The generation of sound by turbulent jets," Advances in Applied Mechanics, Academic Press, Vol. 8, 1964, pp. 103-182.

${ }^{11}$ Ffowcs Williams, J.E., "Some thoughts on the effects of aircraft motion and eddy convection on the noise from air jets," Univ. of Southampton, Dept. of Aer./Astro., USAA Rept. 155, 1960.

${ }^{12}$ Potter, R.C., and Crocker, M.J., "Acoustic prediction methods for rocket engines, including the effects of clustered engines and deflected exhaust flow," NASA-CR$566,1960$.

${ }^{13}$ Hoch, R.G. et al., "Studies of the influence of density on jet noise," First International Symposium on Air Breathing Engines, June 1972.

${ }^{14}$ Sutherland, L.C., "Progress and problems in rocket noise prediction for ground facilities," AIAA Paper 93$4383,15^{\text {th }}$ AIAA Aeroacoustics Conference, Oct. 1993.

${ }^{15}$ Cole, J.N., von Gierke, H.E., Kyrazis, D.T., Eldred, K.M., and Humphrey, A.J., "Noise radiation from fourteen types of rockets in the 1,000 to 130,000 pounds thrust range," WADC Technical Report 57-354, 1957.

${ }^{16}$ McInerny, S., "Rocket Noise- a review," AIAA Paper 90-3981, $13^{\text {th }}$ AIAA Aeroacoustics Conference, Oct. 1990. 
${ }^{17}$ Tam, C.K.W., "On the noise of a nearly ideally expanded supersonic jet," J. of Fluid Mechanics, Vol. 51, Part 1, 1972, pp. 69-95.

${ }^{18}$ Morfey, C.L., Szewczyk, V.M., and Tester, B.J., "New scaling laws for hot and cold jet mixing noise based on geometric acoustics model," J. of Sound and Vibration, Vol. 61, No. 2, 1978, pp. 255-292.

${ }^{19}$ Goebel, S.G., and Dutton, J.C., "Experimental study of compressible turbulent mixing layer," AIAA J., Vol. 29, No. 4, 1991, pp. 453-477.

${ }^{20}$ Kandula, M., and Wilcox, D.C., "An examination of $k-\omega$ turbulence model for boundary layers, free shear layers, and separated flows," AIAA Paper 95-2317, 26 ${ }^{\text {th }}$ AIAA Fluid Dynamics Conference, June 1995.

${ }^{21}$ Phillips, O.M., "On the generation of sound by supersonic turbulent shear layer," J. Fluid Mech., Vol. 9, 1960, pp. 1-28.

${ }^{22}$ Powell, A., "Similarity and turbulent jet noise," $J$. Acoust. Soc. Amer., Vol. 31, 1959, pp. 812-813.

${ }^{23}$ Tam, C.K.W., and Zaman, K.B.M., "Subsonic jet noise from nonaxisymmetric and tabbed nozzles," AIAA J., Vol. 38 , No. 4,2000 , pp. 592-599.

${ }^{24}$ Fortune, V., and Gervais, Y., "Numerical investigation of the noise radiated from hot subsonic jets," AIAA J., Vol. 37, No. 9, 1999.

${ }^{25}$ Fisher, M.J., Lush, P.A., and Harper-Brown, M., "Jet noise," J. of Sound and Vibration, Vol. 28, No. 3, 1973, pp. 563-585.

${ }^{26}$ Narayanan, S., Barber, T.J., and Polak, D.R., "High subsonic jet experiments: Turbulence and noise generation studies," AIAA J., Vol. 40, No. 3, 2002, p.433.

${ }^{27}$ Seiner, J.M., Ponton, M.K., Jansen, B.J., and Lagen, N.T., "The effects of temperature on supersonic jet noise emission," AIAA 92-02-046, 1992.

${ }^{28}$ Tanna, H., An experimental study of jet noise, Part I: Turbulent mixing noise, Part II: Shock Associated Noise, J. of Sound and Vibration, Vol. 50, 1977, pp. 405-444.

${ }^{29}$ Mani, R., "The influence of jet flow on jet noise, Part 1: The noise of unheated jets," J. Fluid Mechanics, Vol. 73, Part 4, 1976, pp. 753-778.

${ }^{30}$ Mani, R., The influence of jet flow on jet noise, Part 2: The noise of heated jets," J. Fluid Mechanics, Vol. 73, Part 4, 1976, pp. 779-793.
${ }^{31}$ Liley, G.M., "The radiated noise form isotropic turbulence with application to the theory of jet noise," $J$. of Sound and Vibration, Vol. 190, No. 3, 1996, pp. 463476.

${ }^{32}$ Massey, K.C., Ahuja, K.K., and Messersmith, N., "Forward flight effects on heated and unheated rectangular jets," AIAA 2002-2483, $8^{\text {th }}$ AIAA/CEAS Aeroacoustics Conference, June 2002.

${ }^{33}$ Kandula, M., and Caimi, R., "Simulation of jet noise with OVERFLOW CFD code and Kirchhoff surface integral," AIAA-2002-2602, $8^{\text {th }}$ AIAA/CEAS Aeroacoustics Conference, June 2002.

${ }^{34}$ Von Karman, Th., in Proc. National Acad. Sci., Vol. 34,1948 , p. 530.

${ }^{35}$ Hinze, J.O., Turbulence, $2^{\text {nd }}$ ed., McGraw-Hill, 1975.

${ }^{36}$ Kolmogorov, A.N., Compt. Rend. Acd. USSR., Vol. 30, 1941, p. 301; Vol. 32, 1941, p. 16.

${ }^{37}$ Bodony, D., and Lele, S.K., "Spatial scale decomposition of shear layer turbulence and the sound sources associated with the missing scales in a large-eddy simulation," AIAA-2002-2454, $8^{\text {ih }}$ AIAAVCEAS Aeroacoustics Conference, June 2002.

${ }^{38}$ Morris, P.J., and Farassat, F., Acoustic analogy and alternative theories for jet noise prediction, AIAA J., Vol. 40, No. 4, 2002, pp. 671-680.

${ }^{39}$ Tam, C.K.W., and Auriault, L., Jet mixing noise from fine-scale turbulence, AIAA J., Vol. 37, No. 2, 1999, pp. 145-153.

${ }^{40}$ Hileman, J., and Samimy, M., "Turbulence structure and the acoustic far field of a Mach 1.3 jet," AIAA J., Vol. 39, No. 8, 2001, pp. 1716-1727. 


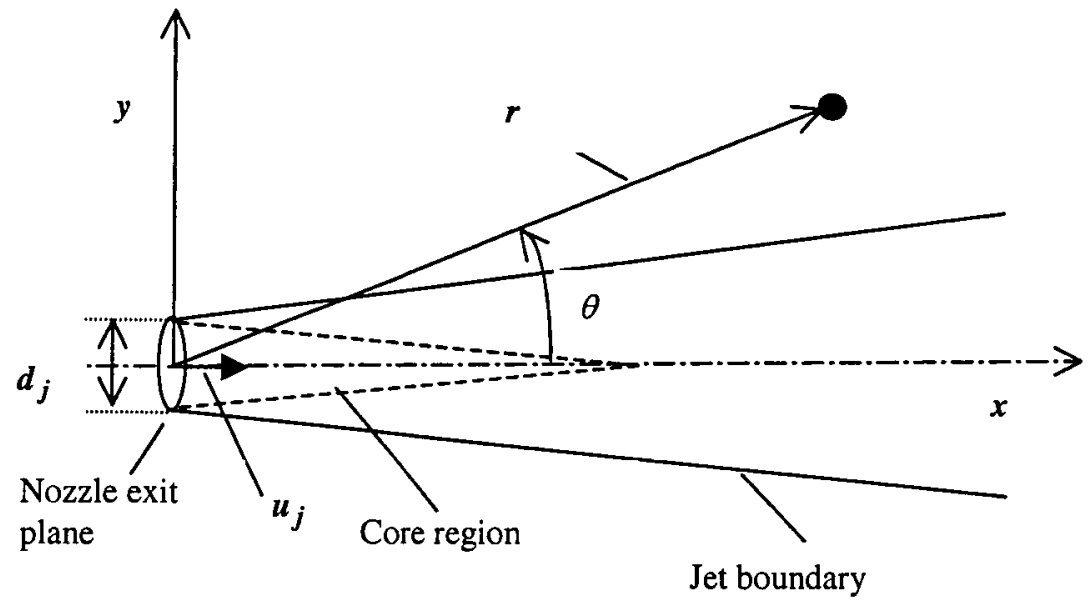

Fig.1 Schematic of the jet configuration.

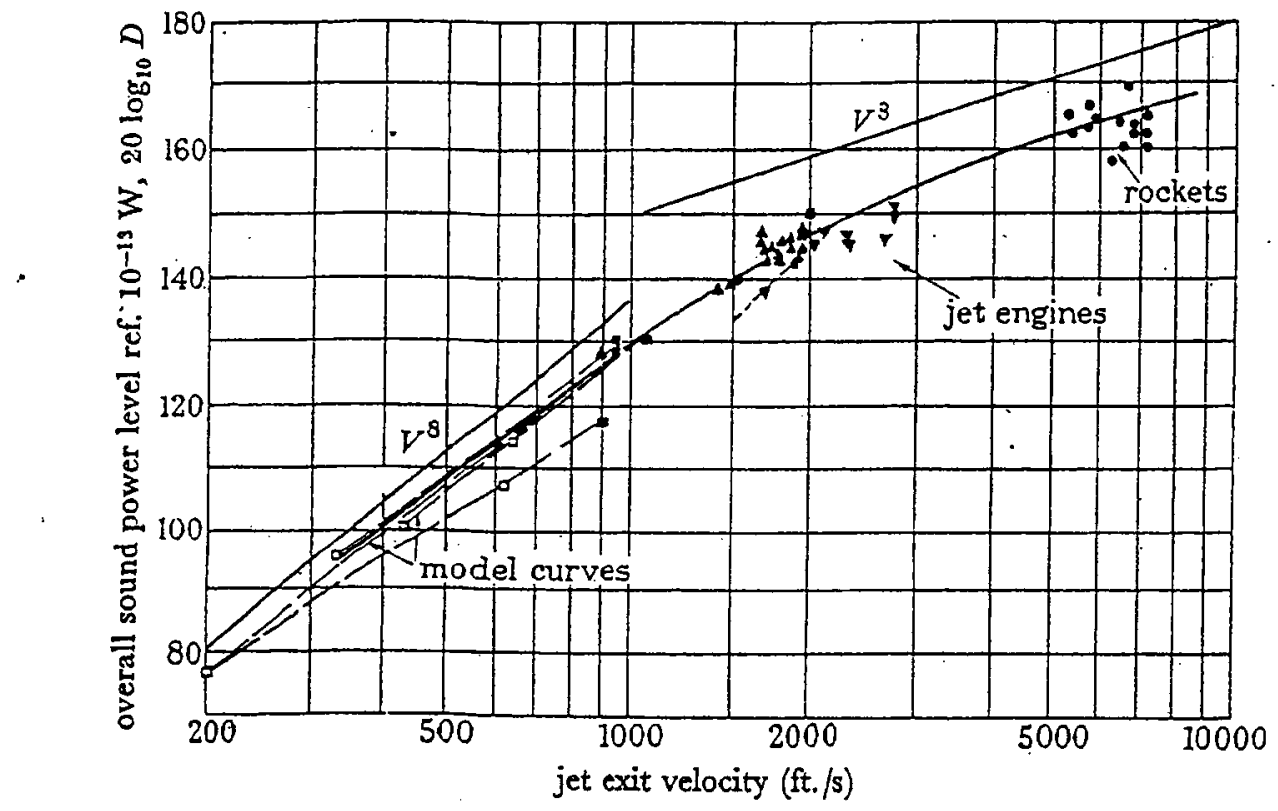

Variation of acoustic power levels from Chobotov \& Powell (1957). •, Rocket; $\checkmark$, turbojet (afterburning); 4 , turbojet (military power); $\square$, exit velocity $>M=0.8 ; 0$, air model (exit velocity $<M=0.8$ ). $D$ is the exit diameter in inches.

Fig. 2 Variation of acoustic power levels and jet velocity,adapted from Ffowcs Williams. ${ }^{7}$ 


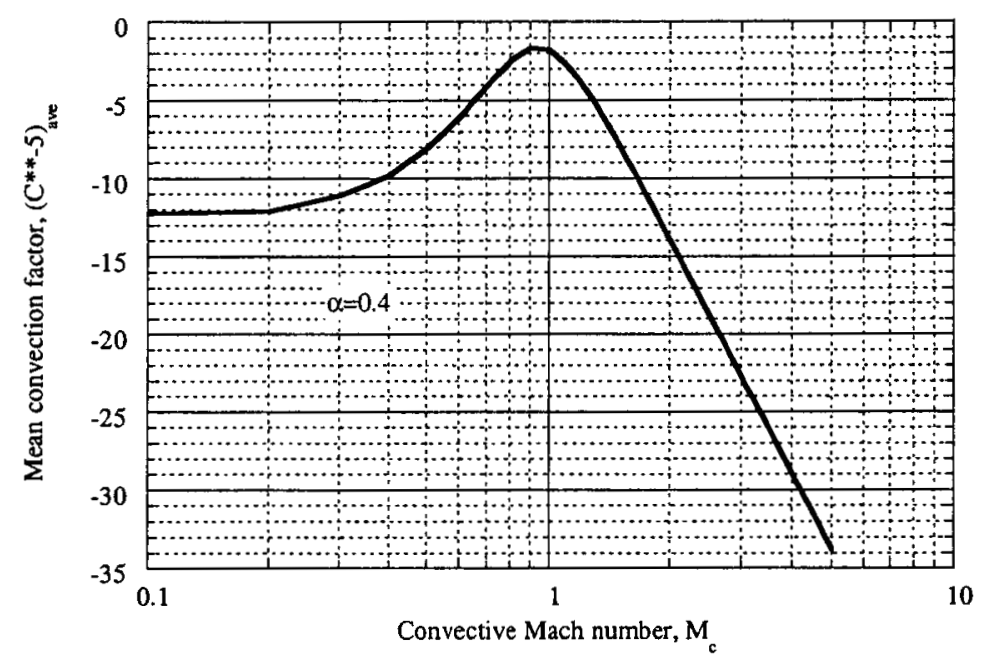

Fig. 3 Variation of mean convective amplification factor with convective Mach number.

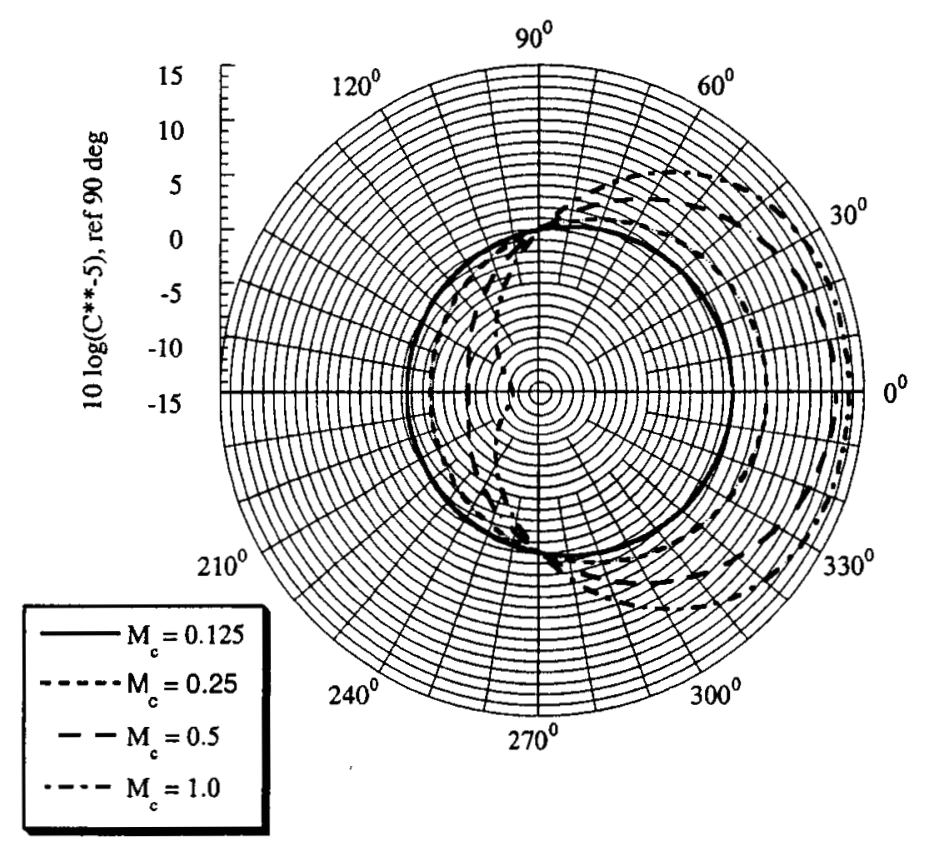

Fig. 4a Dependence of directivity of jet noise with convective Mach number. 


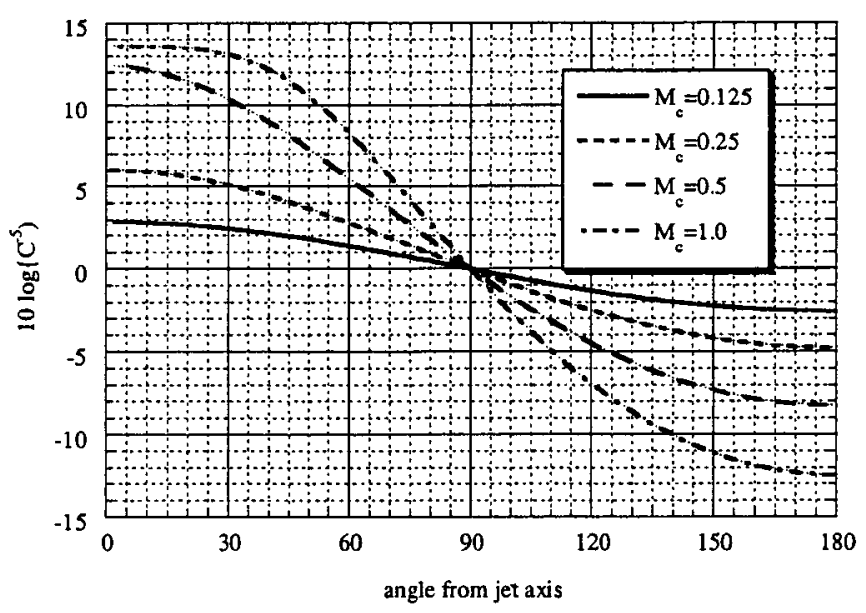

Fig. 4b Directivity as a function of convective Mach number.

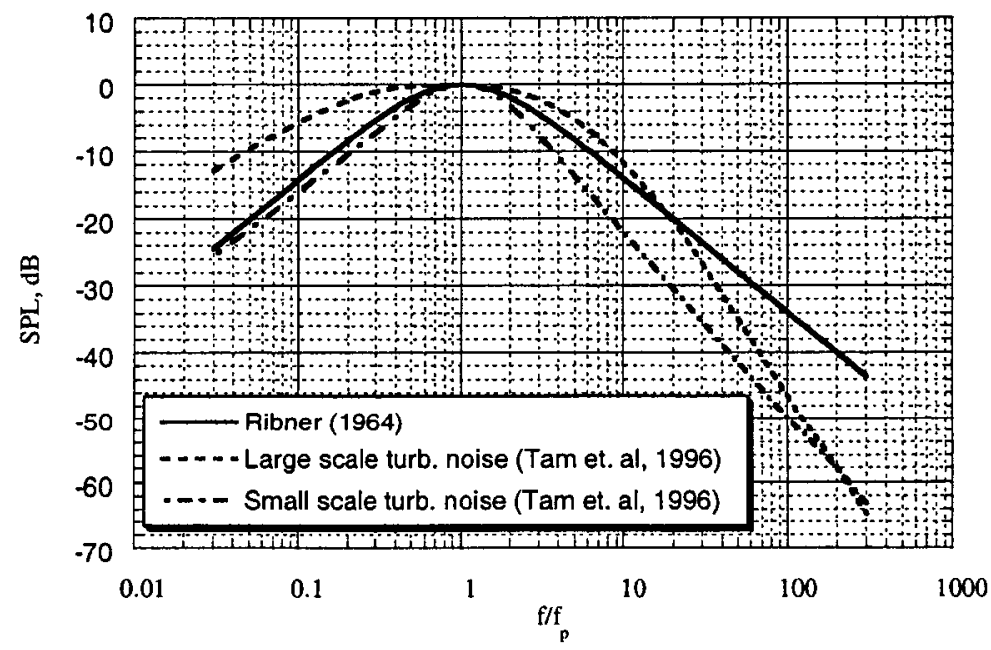

Fig. 5 Similarity spectra due to $\mathrm{Tam}^{1}$ and Ribner. ${ }^{10}$ 


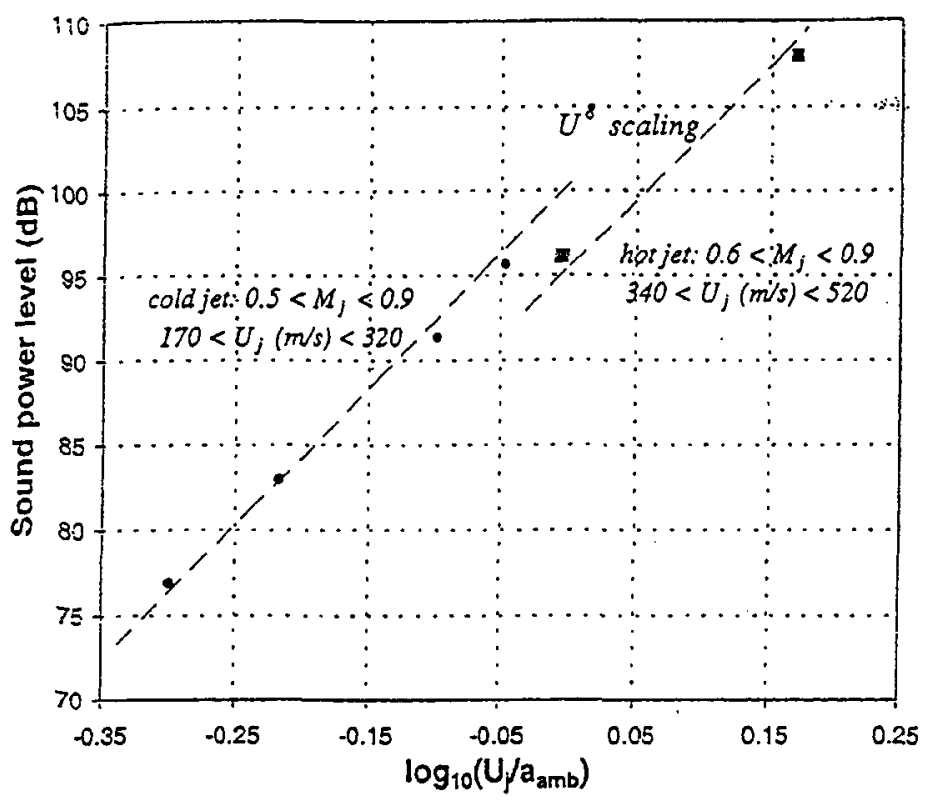

Fig. 6 Dependence of sound power level with jet velocity for cold and hot jets, adapted from Narayanan et al. ${ }^{26}$

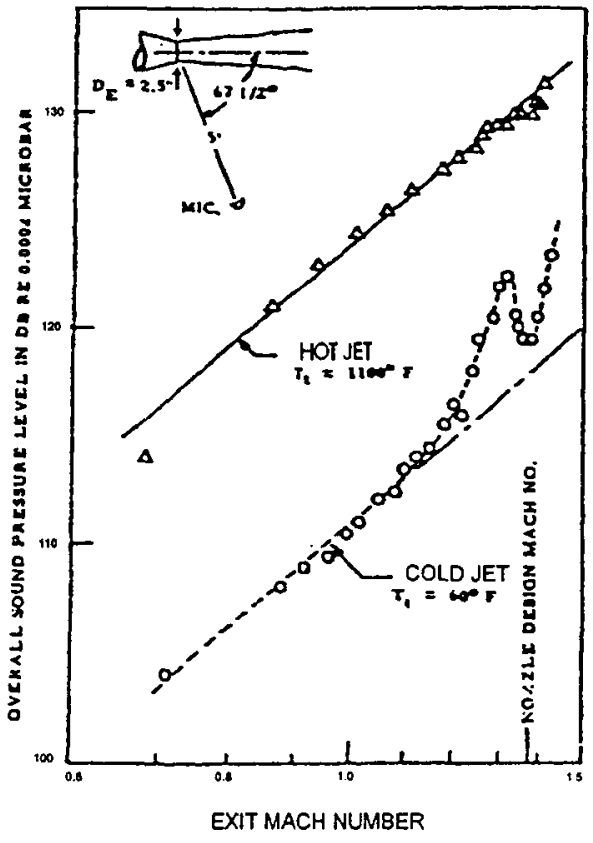

Fig. 7 Variation of overall sound power level with jet Mach number for cold and hot jets, adapted from Morgan et al. ${ }^{4}$ 


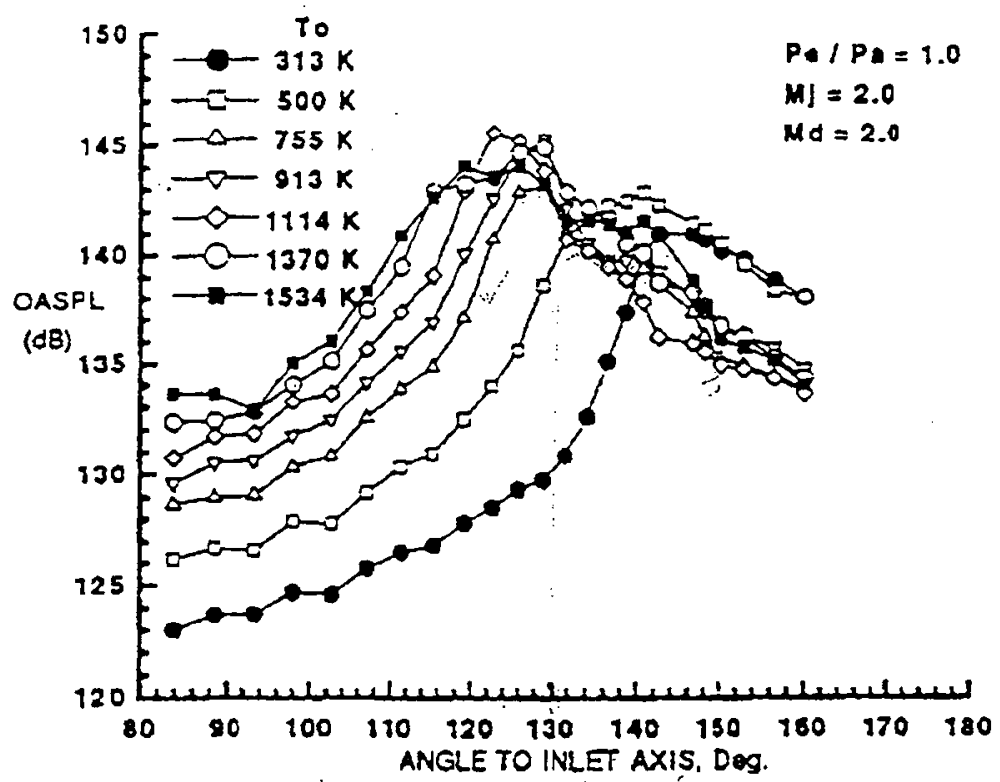

Fig. 8 Dependence of overall sound pressure level on temperature as a function of the angle to the jet axis in supersonic flow, adapted from Seiner et al. ${ }^{27}$

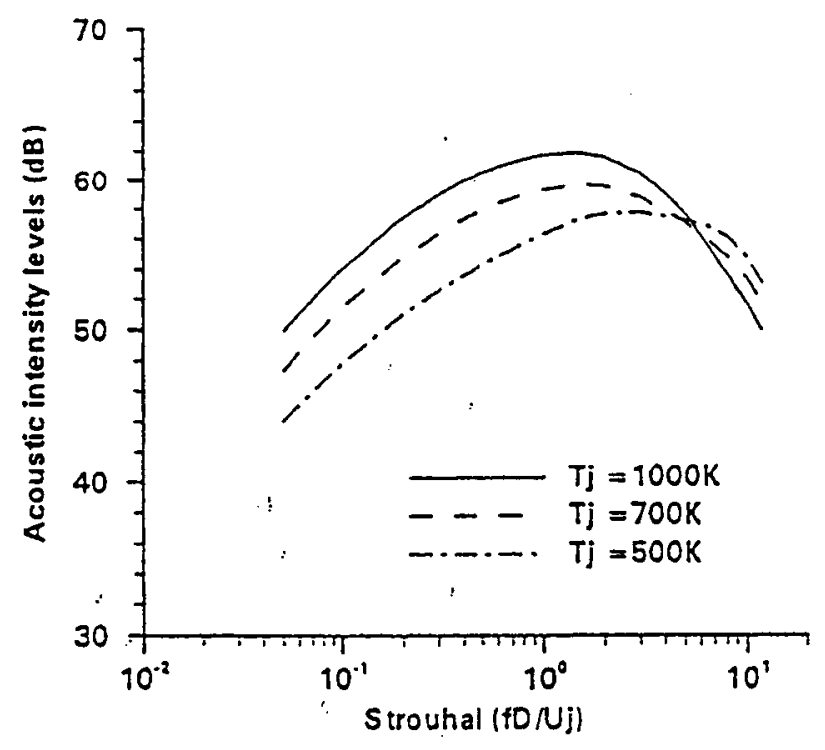

Fig. 9 Effect of jet temperature on acoustic intensity spectra at $90 \operatorname{deg}\left(d_{j}=25 \mathrm{~mm}, u_{j}=125 \mathrm{~m} / \mathrm{s}\right)$, adapted from Fortune and Gervais. ${ }^{24}$ 


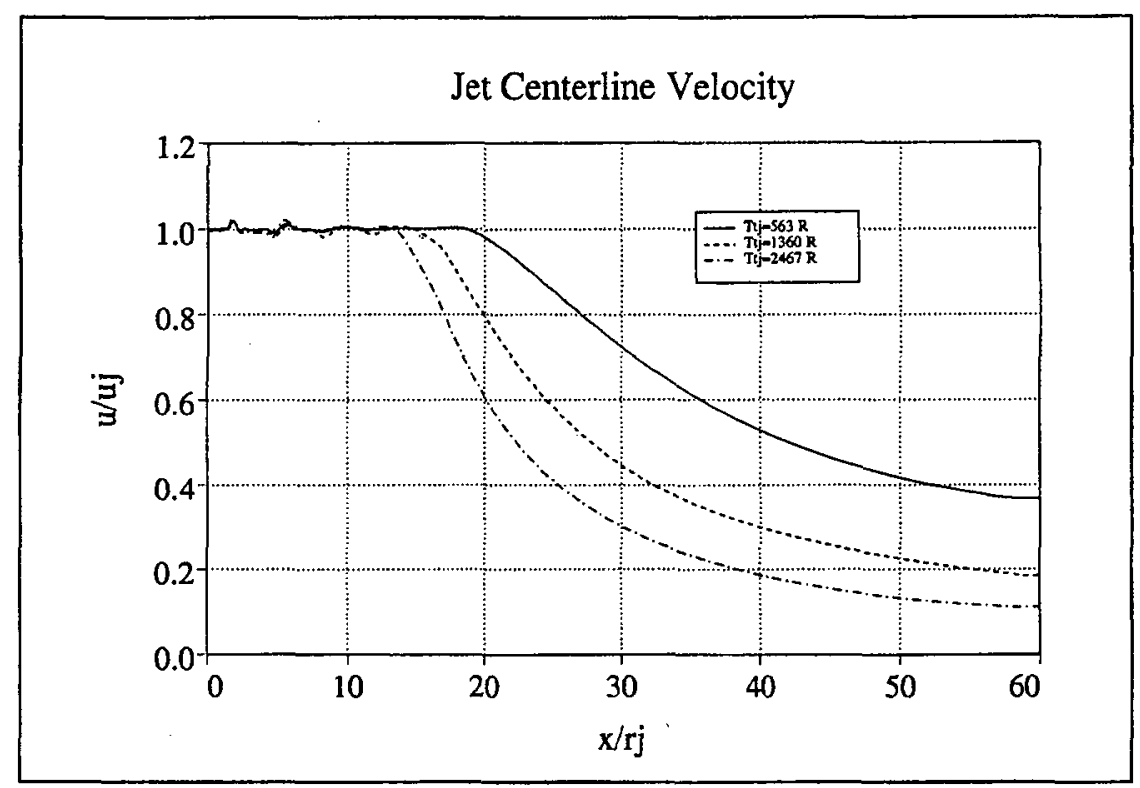

Fig. 10 Variation of computed jet centerline velocity with jet temperature at Mach 2 and an ambient temperature of $540 \mathrm{R}$, illustrating the temperature dependence of supersonic core length.

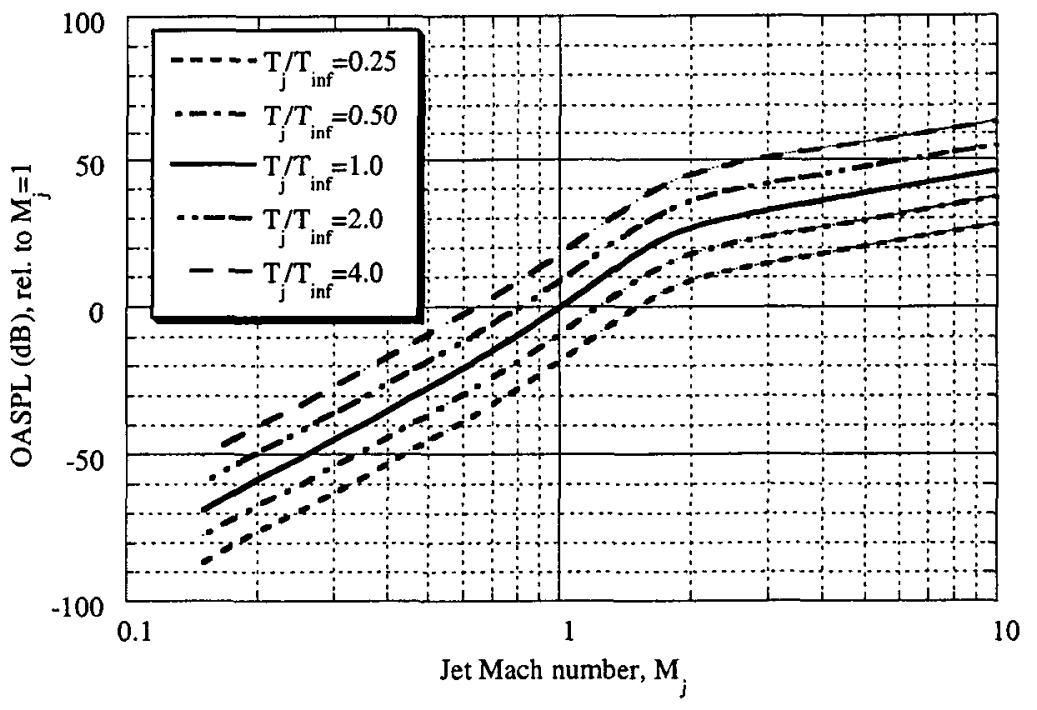

Fig. 11 Effect of temperature ratio on overall sound power level. 


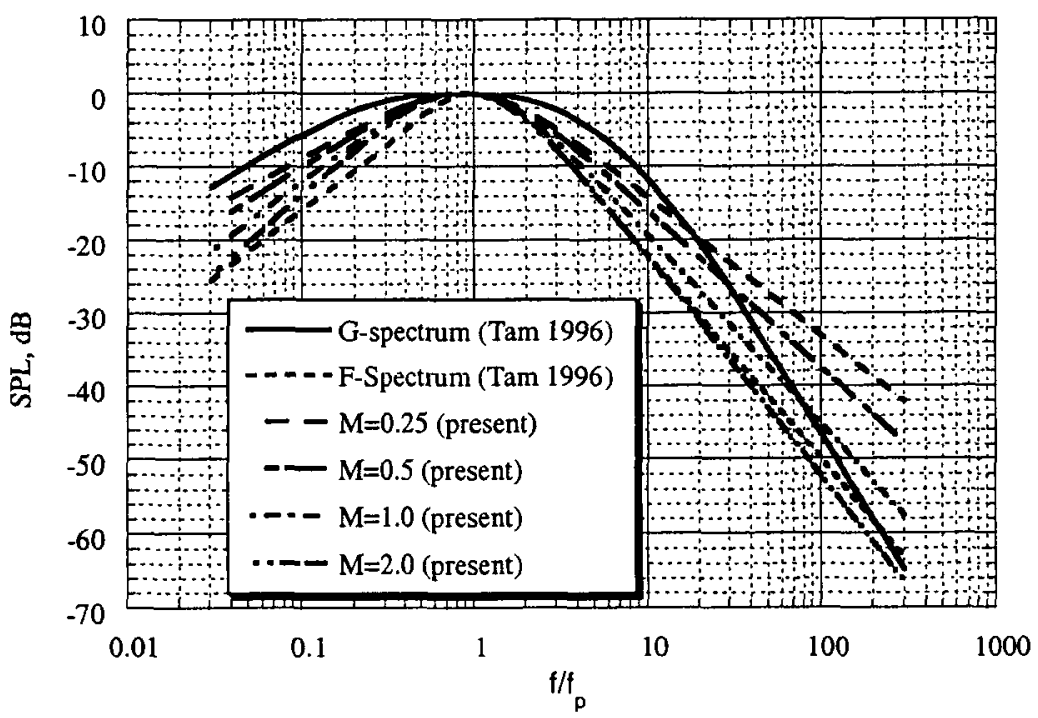

Fig. 12a Similarity spectra for jet noise at $\theta=20 \mathrm{deg}$.

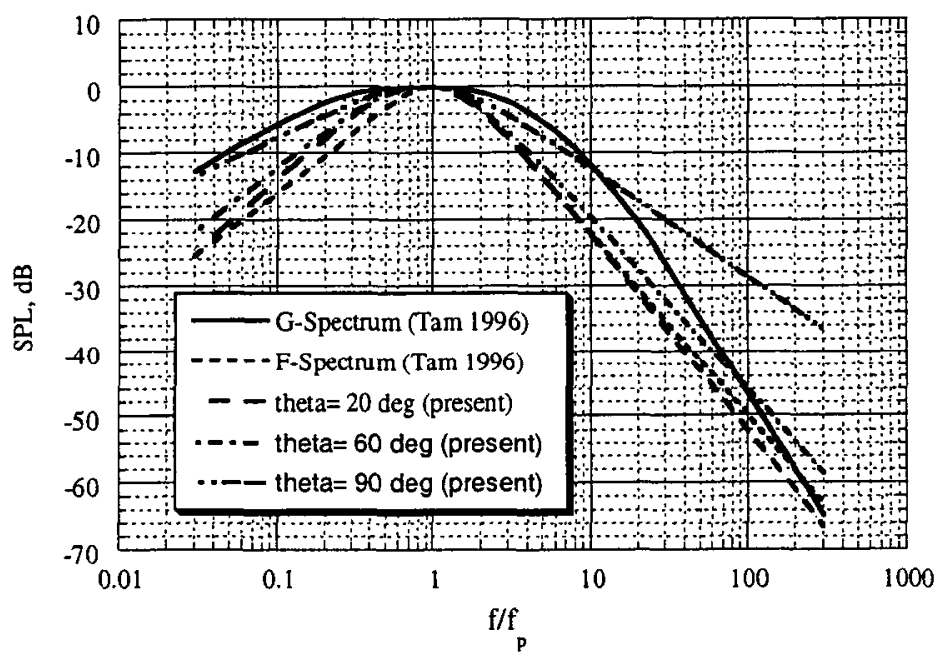

Fig. $12 \mathrm{~b}$ Similarity spectra for jet noise at $M_{j}=2$. 


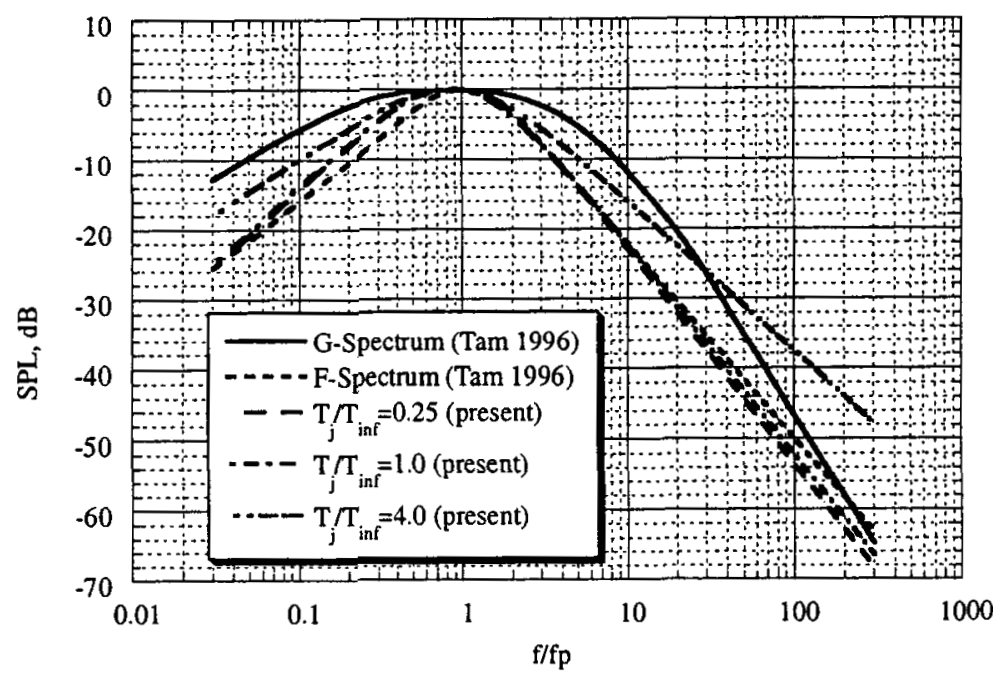

Fig. 12c Effect of temperature on similarity spectra for jet noise at $\boldsymbol{M}_{j}=2$ and $\theta=20 \mathrm{deg}$. 